\title{
VERZEICHNIS DER BERUFE
}

Ästhetiker

Aktionskünstler, Performancekünstler

Angestellter

Apotheker

Arbeiter

Architekt

Archivar

Aufständischer

Bahnangestellter

Ballettmeister, Ballettdirektor

Bankier, Bankangestellter

Beamter

Bearbeiter $\rightarrow$ Herausgeber, Bearbeiter

Bediensteter

Beleuchter, Lichtdesigner

Bergmann

Berufsberater

Bibliothekar

Bildender Künstler

Buchhändler

Buchhalter

Bühnenbildner

Bühnenfechtmeister

Bühnenmaler

Bühnentechniker

Büroangestellter

Chansonsänger

Choreograf

Chorleiter

Dekorateur

Dichter

Diplomat

Direktor am Lehrinstitut

Dirigent

Disponent

Dozent Schauspiel

Dozent Theater

Dozent Theaterregie

Dramatiker

Dramaturg

Drehbuchautor

Drucker

Entertainer

Erfinder

Erzähler

Erzieher $\rightarrow$ Lehrer, Erzieher

Fachautor

Fachautor Bibliographie

Fachautor Biographie

Fachautor Dramaturgie

Fachautor Kunst

Fachautor Lexikon

Fachautor Militär

Fachautor Musik

Fachautor Politik
Fachautor Reise

Fachautor Theater

Fachautor Theologie

Fernsehwissenschaftler $\rightarrow$ Film- und

Fernsehwissenschaftler

Festival-/Festspielleiter

Feuilletonist

Film- und Fernsehwissenschaftler

Filmproduzent

Filmregisseur

Filmtechniker

Firmenleiter $\rightarrow$ Unternehmer, Firmenleiter

Förster, Jäger

Fotograf

Gärtner

Gastwirt

Gebärdensolist

Geisteswissenschaftler

Geistlicher

Geistlicher Dichter

Gelehrter

Germanist

Gesangslehrer

Gewandmeister

Gewerkschafter

Gutsbesitzer, Gutsverwalter

Handwerker

Herausgeber, Bearbeiter

Historiker

Hochschullehrer

Hochstapler

Hörspielautor

Hofbediensteter

Hotelier

Humanist

Humorist

Ingenieur

Innenarchitekt

Inspizient, Spielwart

Instrumentalist

Interdisziplinärer Künstler

IT-Spezialist

Jäger $\rightarrow$ Förster, Jäger

Journalist

Jurist

Kabarettautor

Kabarettist

Kabarettleiter, Kabarettbesitzer

Karikaturist

Kaufmann

Klangkünstler

Komparserieleiter

Komponist

Korrepetitor

Kostümbildner 
Kostümforscher

Künstler

Künstleragent

Künstlerischer Berater

Kulturmanager

Kunsthandwerker

Kunsthistoriker

Kunstmaler

Kunstpfeifer

Landwirt

Lehrer, Erzieher

Lehrer an Theaterschulen

Leiter von Filmgesellschaften

Librettist

Lichtdesigner $\rightarrow$ Beleuchter, Lichtdesigner

Liedermacher

Literatur- und Sprachwissenschaftler

Lyriker

Mäzen

Magister

Manager

Marionetten-, Puppenspieler

Maskenbildner

Medienkünstler

Mediziner, Pfleger

Militär

Mitglied der Reichskulturkammer

Modedesigner

Model

Moderator

Museumsfachmann

Musicaldarsteller

Musikalienhändler

Musikdozent an Hochschule, Akademie

Musiker

Musikinstrumentenbauer

Musiklehrer

Musikvereinsleiter

Musikverleger

Musikwissenschaftler

Naturwissenschaftler

Notenschreiber

Performancekünstler $\rightarrow$ Aktionskünstler, Performancekünstler

Pfleger $\rightarrow$ Mediziner, Pfleger

Philosoph

Pilot

Politiker

Politischer Redner

Polizeibeamter

Postbeamter

Produktionsleiter

Produzent

Psychologe

Puppenbauer

Puppenspieler $\rightarrow$ Marionetten-, Puppenspieler Raumstratege
Redner

Referent

Regisseur

Reisender

Requisiteur

Rhetoriklehrer, Sprecherzieher

Rundfunkmitarbeiter

Sänger

Sammler

Satiriker

Schauspieler

Schauspiellehrer

Schneider

Schriftsteller

Seemann

Sekretär

Souffleur

Sozialarbeiter

Sozialwissenschaftler

Spielbankangestellter

Spielwart $\rightarrow$ Inspizient, Spielwart

Sportler

Sprachbildner

Sprachwissenschaftler $\rightarrow$ Literatur- und

Sprachwissenschaftler

Sprecherzieher $\rightarrow$ Rhetoriklehrer,

Sprecherzieher

Steuerberater

Stiftungsleiter

Stimmkünstler

Tänzer

Tanzlehrer

Techniker

Technischer Direktor - Theater

Theater - Hausangestellter

Theater - Verwaltungsangestellter

Theaterbesitzer

Theatergründer

Theaterleiter

Theatermaler, Theaterplastiker

Theatermanager

Theaterpädagoge

Theaterplastiker $\rightarrow$ Theatermaler, Theaterplastiker

Theaterreformer

Theaterwissenschaftler

Theologe

Tiermimiker, Tierimitator

Tondesigner $\rightarrow$ Video- und Tondesigner

Tontechniker $\rightarrow$ Video- und Tontechniker

Transporteur

TV-Leiter

Übersetzer

Unternehmer, Firmenleiter

Verbandsfunktionär

Verbandsgründer, Verbandsleiter

Verfasser von Ballettprogrammen

Verleger, Verlagsangestellter 
Versicherungsmitarbeiter

Video- und Tondesigner

Video- und Tontechniker

Volksliedforscher

Vortragskünstler

Wächter
Wagnerforscher

Werbeleiter

Werbetexter

Wirtschaftswissenschaftler

Zensor

Zirkuskünstler 
